\title{
Survey of spontaneous pneumothoraces in the Royal Air Force
}

\author{
I. R. CRAN AND C. A. RUMBALL \\ From the Royal Air Force Chest Unit, King Edward VII Hospital, Midhurst, Sussex
}

\begin{abstract}
Nine hundred and ninety-four cases of spontaneous pneumothorax which occurred in Royal Air Force personnel over a period of 22 years are reviewed. They are analysed in relation to age, side of occurrence, activity at the time of onset, and seasonal occurrence. Some clinical and radiological findings are presented and the incidence of recurrence is described (the possible association with emphysematous bullae is mentioned). Methods of treatment are discussed and those found most suitable for the special requirements of R.A.F. personnel are described. Spontaneous pneumothorax is thought to be more commonly diagnosed now and an increasing incidence in the R.A.F. in recent years is demonstrated.
\end{abstract}

Brock (1948), in his article on recurrent and chronic spontaneous pneumothoraces, stated: 'Statistics are usually tedious and often disappointing in what they convey, but it is still necessary to present them albeit in as brief and simple a way as possible.'

With these words of wisdom ringing in our ears, it is proposed to survey 994 spontaneous pneumothoraces that have been recorded in Royal Air Force personnel between 1941 and 1962. These include 158 recurrences. The 994 spontaneous pneumothoraces therefore involved 836 patients.

Several surveys of spontaneous pneumothoraces have been carried out in the past, and the increasing number of these reported series indicates that the condition is not rare. We believe that it is on the increase. Perry (1939) reviewed 85 cases covering a period of 14 years. Cliff (1957) reviewed 163 cases in Royal Navy personnel covering a period of 11 years. We are reviewing 994 cases covering a period of 22 years.

None of these was a patient suffering from pulmonary tuberculosis who might have developed a spontaneous pneumothorax during the course of his illness.

Gobbel, Rhea, Nelson, and Daniel (1963), in their article on spontaneous pneumothorax, reviewed the earlier literature on the subject of pneumothorax and stated that Laennec, as early as 1819 , described pneumothoraces present at necropsies without evidence of tuberculosis ; Biach (1880) collected 918 instances of pneumothorax in
Vienna, of which $715(80 \%)$ were attributed to tuberculosis ; but it was Kjaergaard (1932) who established that most spontaneous pneumothoraces are non-tuberculous.

All the cases recorded in this present series occurred in men; it is known that the condition occurs more commonly in men than in women. The ages of the patients ranged from 16 to 50 years. It is appreciated that a number of cases of spontaneous pneumothorax occur in older age groups associated with chronic bronchitis and emphysema, but by the time this happens the individual has usually left the Royal Air Force.

Spontaneous pneumothorax is known to occur most commonly in the late teens or early twenties and Table I shows the incidence according to age group. It will be noted that in this Royal Air 을 Force series $73 \%$ occurred between the ages of 15 and 24 years. This is similar to the findings in

T A B L E I

AGE INCIDENCE

\begin{tabular}{|c|c|c|}
\hline & Age Group & No. of Cases \\
\hline \multirow[t]{2}{*}{. } & $\begin{array}{c}15-19 \\
20-24 \\
25-29 \\
30-34 \\
35-39 \\
40-44 \\
45-50 \\
50- \\
\text { Unknown }\end{array}$ & $\begin{array}{r}244 \\
483 \\
120 \\
75 \\
34 \\
14 \\
8 \\
1 \\
15\end{array}$ \\
\hline & Total & 994 \\
\hline
\end{tabular}


other series, and in his review of the literature Cliff (1957) showed that many authors had found a similar age incidence.

\section{SIDE OF OCCURRENCE}

Various series of cases of spontaneous pneumothorax that have been reviewed in the literature over the past few years have shown that the condition is more common on the left side, and Table II shows the breakdown of these 994 spontaneous pneumothoraces into their respective sides. The higher occurrence on the left side in this series is statistically significant at $5 \%$ and is probably brought to light by the larger number of cases under consideration. No reason for this preponderance is forthcoming.

T A B L E I I

SIDE OF CHEST AFFECTED

\begin{tabular}{|c|c|}
\hline Side Affected & No. of Cases \\
\hline $\begin{array}{l}\text { Left } \\
\text { Right } \\
\text { Both } \\
\text { Not recorded }\end{array}$ & $\begin{array}{r}518 \\
437 \\
16 \\
23\end{array}$ \\
\hline Total & 994 \\
\hline
\end{tabular}

\section{ACTIVITY AT TIME OF ONSET}

It has been stated in the past that spontaneous pneumothorax is likely to occur as a result of severe exercise or strain whilst doing heavy lifting. In our experience this has not been so. In order to avoid complexity, exercise has been taken to mean any activity that was more strenuous than walking at a normal pace on the level. This is quite arbitrary but distinguishes between onset at rest and onset during exercise.

Table III shows that in 107 patients the condition occurred at rest, in 358 during exercise, and in eight whilst the patient was flying; in 521 no remarks were recorded as to the activity at the time of onset and it can be assumed that exercise was not severe.

T A B LE I I I

ACTIVITY AT TIME OF ONSET

\begin{tabular}{l|c}
\hline \multicolumn{1}{c|}{ Activity } & No. of Cases \\
\hline At rest & 107 \\
During exercise & $358\left\{\begin{array}{l}\text { Slight } \begin{array}{r}159 \\
\text { Moderate } \\
\text { Severe } 84\end{array} \\
\text { In the air }\end{array}\right.$ \\
\hline
\end{tabular}

TIME OF YEAR OF ONSET

It has been suggested that spontaneous pneumothorax occurs more commonly in the winter months, there being an increased likelihood associated with upper respiratory tract infections and consequent coughs which occur mainly in the winter months.

Table IV shows the time of year that the 994 spontaneous pneumothoraces occurred and, apart from an increased number occurring in January and a lesser number in June, the figures do not appear to be significant.

T A B L E IV

TIME OF YEAR OF SPONTANEOUS PNEUMOTHORAX

\begin{tabular}{l|c} 
Month & No. of Cases \\
\hline January & 107 \\
February & 89 \\
March & 82 \\
April & 74 \\
May & 85 \\
June & 67 \\
July & 84 \\
August & 80 \\
September & 73 \\
October & 75 \\
November & 89 \\
December & 83
\end{tabular}

Not known 6

If, however, these numbers are grouped in quarters, we find that there is a slight winter preponderance: 279 occurred in November to January ; 245 in February to April ; 236 in May to July; and 228 in August to October.

Only 120 patients gave a history of recent cough in the weeks before experiencing a spontaneous pneumothorax. Seventy-two were unaware of the fact that they had a spontaneous pneumothorax and these were detected by routine radiography of the chest. Only 18 patients were recorded as being totally incapacitated by the occurrence, whilst 904 were classified as being sufficiently incapacitated to seek medical attention.

\section{RADIOLOGICAL FINDINGS}

Spontaneous pneumothorax is commonly believed to be due to the rupture of small blebs or bullae on the visceral surface of the lung, or occasionally to the rupture of a larger emphysematous cyst, although it is commonly found that when the lung re-expands it appears to be normal radiologically. Table V shows that only 15 patients were recorded 
T A B L E V

RADIOLOGICAL FINDINGS

\begin{tabular}{l|c}
\hline & No. of Cases \\
\hline Fluid & 192 \\
Cysts & 15 \\
Blebs or bullae & 69 \\
\hline
\end{tabular}

as having cysts and 69 as showing blebs or bullae. Fluid was present in the pleural cavity in 192 of the spontaneous pneumothoraces under review.

\section{RECURRENCES}

Of 836 patients, 133 had 158 recurrences of spontaneous pneumothorax $(18.7 \%) ; 118$ were on the same side as the original occurrence and 37 on the opposite side; three were not recorded.

The most likely time for a recurrence was within the first 12 months of the original event, and after the second year the likelihood of recurrence became less. The breakdown of these 158 recurrences into the years following the initial occurrence is shown in Table VI. Twenty-one patients had more than one recurrence, two having had four, and one having had five.

T A B L E V I

YEAR OF RECURRENCE

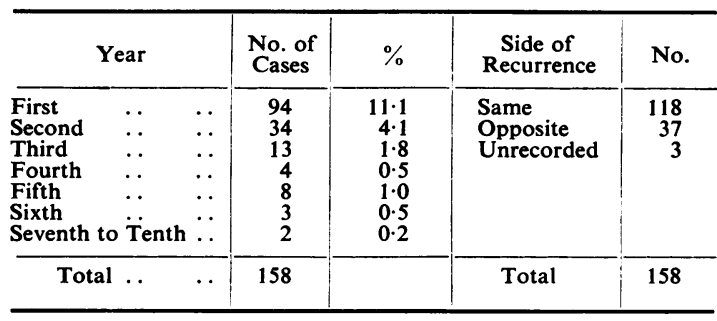

\section{TREATMENT}

The majority of patients who experienced a spontaneous pneumothorax were not unduly distressed at the time; the lungs re-expanded satisfactorily on modified bed rest alone, and in this series this was the only form of treatment given to 763 patients (roughly $75 \%$ ).

The removal of air and/or fluid was required in 47 patients before re-expansion could be obtained. In 83 an indwelling tube connected to an underwater seal was required before re-expansion could be obtained. Fourteen patients required thoracotomy to obtain satisfactory re-expansion.

It is present policy in the Royal Air Force to allow ground staff to have a single pneumothorax without advising pleurodesis, provided the lung re-expands satisfactorily. If a patient has a further spontaneous pneumothorax, either on the same or opposite side, then pleurodesis is advised. It should be appreciated that members of the Royal $\nRightarrow$ Air Force must be fit to serve throughout the world and sometimes in remote areas, and that the recurrence of a pneumothorax in such a place may well be disastrous to the individual. The result of this policy is that pleurodesis is advised more frequently in the Royal Air Force than in civilian life.

It should further be considered that ground staff who experience a single pneumothorax will $\stackrel{N}{N}$ be retained on home service for a period of two 웅 years before being allowed to proceed overseas, and one has only to refer to Table VI to realize $\mathcal{D}$ the importance of this two-year period of observation. In members of aircrew, by which is meant pilots, navigators, flight engineers, etc. (i.e., those who fly aircraft and are responsible for the safety of these aircraft), pleurodesis is mandatory after a single spontaneous pneumothorax if they wish. to continue their flying duties.

In the past, pleurodesis has been performed with various sclerosing agents. In this series, 125 patients required pleurodesis and the agents used were silver nitrate, olive oil, and kaolin, as shown in Table VII.

T A B LE VII

PLEURODESIS

\begin{tabular}{c|c|c|}
\hline No. of Cases & Agent \\
\cline { 2 - 3 } 70 & Silver nitrate \\
29 & Olive oil \\
17 & Kaolin \\
9 & Not stated \\
\cline { 2 - 3 } & Total \\
\hline
\end{tabular}

Recurrence is not unknown after attempted pleurodesis. Four patients had a recurrence on the same side between nine months and three years following pleurodesis with silver nitrate. One had a recurrence following pleurodesis with olive oil and one following the instillation of kaolin. Six had a pneumothorax on the opposite side following pleurodesis.

Ground staff who have pleurodesis performed in the Royal Air Force are kept under observation in a home category for a period of one year and, if there is no recurrence, they are given a world-wide category but have an annual radiograph of the chest for follow-up purposes.

Members of aircrew who have had a pleurodesis are kept on ground duties for three months 
after discharge from hospital and are then readmitted to hospital, when an artificial pneumothorax is attempted. If no pleural space can be demonstrated, either anteriorly or posteriorly, then they are given a full flying category, based on home service for one year and then a worldwide category with annual chest radiographic follow-up. If a space is obtained and the lung is free with no adhesions, further pleurodesis is advised and usually accepted.

In a number of patients in whom an artificial pneumothorax was attempted three months after pleurodesis, partial obliteration of the pleural space was obtained, and in these double the quantity of air used for induction was introduced the next day, this being equivalent to the intrapleural pressure of air at sea level when subjected to an altitude of approximately $15,000 \mathrm{ft}(4,572$ $\mathrm{m}$.$) ; the majority of modern aircraft, although$ flying at a considerably higher altitude, rarely have a cabin pressure in excess of 8,000 to 9,000 ft $(2,438$ to $2,743 \mathrm{~m}$.).

If induction of double the quantity of air gave rise to no untoward symptoms of pain and if chest radiographs showed that the adherent area was intact, the patients were permitted to return to full flying duties in a home category for one year and were then given a world-wide category with annual chest radiographic follow-up.

When a sclerosing agent has been introduced into the pleural cavity, the visceral and parietal pleura probably become thickened, provided it is seen that there is a reasonable pleural reaction at the time; and although an artificial pneumothorax can be induced, there is, in our opinion, little likelihood of a recurrence of a spontaneous pneumothorax because small blebs or bullae on the lung surface will be covered by thickened visceral pleura and therefore will be unlikely to rupture spontaneously. Unfortunately, this supposition is difficult to prove, but pleural biopsies of the parietal pleura have been performed before pleurodesis, immediately afterwards, and three months after using silver nitrate; these show that the parietal pleura has become thickened, and therefore a similar state of affairs probably exists on the visceral pleura.

We continue in the Royal Air Force to test out all aircrew members by artificial pneumothorax after pleurodesis and, as far as we are concerned, we would rather fly with a pilot who has been shown to have pleurodesis than with one who has probable thickening of the visceral pleura.

In conclusion, it appears that spontaneous pneumothorax is not an uncommon condition in the Royal Air Force; probably it is no more common than in civilian life, but, owing to the nature of the Service, we are more conscious of the condition and treat it more seriously than civilian doctors.

Table VIII suggests that spontaneous pneumothorax is increasing in prevalence.

\section{T A B L E V I I I}

STANDARDIZED INCIDENCE RATES OF SPONTANEOUS PNEUMOTHORAX IN THE R.A.F. BASED ON AGE DISTRIBUTION IN 1958

\begin{tabular}{c|c} 
Year & $\begin{array}{c}\text { Standardized Rate/ } \\
1,000 \text { Strength }\end{array}$ \\
\hline 1949 & $0 \cdot 20$ \\
1950 & $0 \cdot 23$ \\
1951 & $0 \cdot 24$ \\
1952 & $0 \cdot 25$ \\
1953 & $0 \cdot 26$ \\
1955 & $0 \cdot 27$ \\
1956 & $0 \cdot 30$ \\
1957 & $0 \cdot 26$ \\
1958 & $0 \cdot 28$ \\
1959 & $0 \cdot 37$ \\
1960 & $0 \cdot 39$ \\
1961 & $0 \cdot 42$ \\
1962 & $0 \cdot 48$ \\
1963 & $0 \cdot 43$ \\
1964 & $0 \cdot 36$ \\
\hline
\end{tabular}

These figures have been standardized against the strength of the Royal Air Force in 1958 and are shown as the rate per thousand. From 1958 onward there has been a statistically significant increase.

The figures have been obtained from the Royal Air Force by kind permission of the Director General Medical Services.

\section{REFERENCES}

Biach, A. (1880). Zur Aetiologie des Pneumothorax. Wien. med. Wschr., 30, 431

Brock, R. C. (1948). Recurrent and chronic spontaneous pneumothorax. Thorax, 3, 88 .

Cliff, J. M. (1957). Spontaneous pneumothorax in the Royal Navy. Proc. roy. Soc. Med., 50, 517.

Gobbel, W. G., Rhea, W. G., Nelson, I. A., and Daniel, R. A. (1963). Spontaneous pneumothorax. J. thorac. cardiovasc. Surg., 46, 331

$\mathrm{K}$ jaergaard, H. (1932). Spontaneous pneumothorax in the apparently healthy. Acta med. scand., Suppl. 43.

Laennec, R. T. H. (1819). De l'auscultation mediate, ou traité du diagnostic des maladies des poumons et du caur. Vol. 1. Brosson and Chaudé, Paris.

Perry, K. M. A. (1939). On spontaneous pneumothorax. Quart. J. Med., n.s. 8, 1 . 